\title{
"JANTAR EM FAMÍLIA" DE KAZUO ISHIGURO: O Texto e o Subtexto
}

\author{
Brunilda Tempel Reichmann*
}

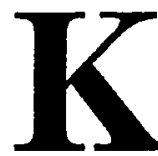

azuo Ishiguro nasceu em Nagasaki, Japão, cm 1954. Desde os 6 anos, no entanto, vive na Inglaterra. Freqüentou a Universidade de Kent em Canterbury e a Universidade de East Anglia. Atualmente reside em Londres. Pelos seus romances Uma Pálida Visão dos Montes ', Um Artista do Mundo Flutuante ${ }^{2}$ e Vestigios do Dia, ${ }^{3}$ Ishiguro recebeu respectivamente o prêmio Winifred Holtby da Royal Society of Literature, o prêmio Whitbread Book of the Year (1986) e o 1989 Booker Prize. Seus romances já foram traduzidos para mais de 12 idiomas e Vestigios do Dia foi adaptado para o cinema em 1993. Como filme encontrou também calorosa receptividade pelo público. Aos 41 anos, Ishiguro é considerado um dos grandes escritores ingleses.

* Universidade Foderal do Paraní.

I ISHIGURO, K. A Pale View of Hills. New York : Vintage Books, 1986.

2 Id. An Artist of the Floating Workd. New York: Vintage Books, 1986.

3 Id. Remains of the Day. New York: Vintage Books, 1988. 
O conto "Jantar em Familia", 4 assim como os romances de Ishiguro, apresenta uma narrativa extremamente delicada, uma visão suavemente irônica e elegíaca e um mistério insondável, de uma sutileza completamente envolvente - características raras na litcratura de língua inglesa nos anos 80 e 90.

Como parte do mistério que caracteriza o texto, encontramos a resistência do mesmo para elucidar a grande questão suscitada pelo subtex to: "O pai japonês mata seus filhos e se suicida?" A impossibilidade de responder-se a esta pergunta faz com que nos tornemos incansáveis leitores à procura de indicios dentro da narrativa que nos possibilite encontrar uma resposta. Não importa, no entanto, quanto busquemos. Nem o texto nem o subtexto fornece uma resposta à pergunta. Percebemos, sim, uma tendência ou inclinação para uma resposta positiva à pergunta. Não temos evidência definitiva, no entanto, para fazermos tal afirmação. A resposta fica suspensa, assim como o texto, que durante alguns momentos parece estar de tacones lejanos $\mathrm{e}$ pairar a uma certa distância acima do subtexto e, em outros momentos, confundir-se totalmente com aquele. Quando há distância entre os dois, esta cria um espaço morto que torna a narrativa ainda mais renitente à sua própria revelação.

Se tomarmos o texto e o subtexto, veremos que o primeiro é marcado por um núcleo metafórico - as canhoneiras mal coladas, e o segundo é revelado principalmente através de dois núcleos simbólicos - o poço e o jantar.

A imagem das canhoneiras mal coladas ${ }^{5}$ remete o leitor ao problema sóciocultural, familiar e individual, pois o personagem central e narrador relata as conseqüencias de desprender-se das amarras de sua terra natal e ser continuamente confrontado pelos membros da sociedade de seu país e de sua família. Para o velho pai japonês, o respeito à tradição, à soberania e aos costumes nipônicos são a única razão da existência.

Assim como alguns escritores "ingleses", tais como Byron, Conrad, Forster, Durrell, Fowels, que usam paises estrangeiros e exóticos como o universo fiecional de suas personagens, Ishiguro usa o Japão com a mesma finalidade. Com uma grande diferença, no entanto. Ȧ semelhança de Joyce, que abandona a Irlanda, mas que torna seu país natal o espaço poético de todos seus escritos, Ishiguro, com exceção do romance Vestígios do Dia, toma a mesma atitude. O Japão acompanha o romancista em sua trajetória dentro da literatura

4 ISHIGURO. K . "Family Supper". In: BRADBURY, M. ed. The Penguin Book of Modern British Short Stories, England: Penguin Books, p.434-442. Tradução de Brunilda Tempel Reichmann. Todas as referèncias a esse conto incluirão o nome do autor, Ishiguro, e o número da página da versảo original. Cópia do conto traduzido pode ser solicitada ao Departamento de Letras Estrangeiras Modernas da Universidade Federal do Paraná.

5 Ibid., p.439. 
inglesa. “Jantar em Família” não é exceção. O velho pai, viúvo, "abandonado pelos filhos", é o protótipo do japonès que não aceita mudanças sociais $\mathrm{c}$ culturais nem tampouco características no comportamento dos filhos que não aquelas que fazem parte da tradição nipônica.

Meu pai era um homem com uma aparência marcante; tinha um maxilar grande $\mathrm{e}$ inflexivel e furiosas sobrancelhas negras. Agora, quando me recordo, creio que cle se parecia com Chou En-Lai; sei, no entanto, que meu pai não apreciaria a comparação, por ser extremamente orgulhoso do puro sangue samurai que corria nas veias da família. Sua aparência habitual não convidava a uma conversa descontraída; nem ajudava muito sua estranha mancira de fazer cada comentário como se fosse definitivo. ${ }^{6}$

Tanto o narrador anônimo, como sua irmā, Kikuko, rompem com os valores mais importantes para o velho pai - of filho de forma ostensiva e aberta, a filha de forma sorrateira e velada.

Em termos culturais e familiares, torna-se evidente que o pai jamais aceitou ou aceitará a decisão do filho de mudar-se para a Califómia. Agora de retorno, temporário ou definitivo, ao país natal, muitos são os momentos nos quais o pai cobra do fillho a escolha que tizera de abandonar o Japão. Através de todo o texto, essa cobrança assume várias manifestações, sendo uma delas a quase impossibilidade de comunicaçāo entre pai e filho.

Inevitavelmente nossa conversa, desde minha chegada ao aeroporto, era pontuada por longas pausas... Depois de algum tempo, a conversa tinha se tornado ainda mais difícil do que antes da chegada de Kikuko... Quase não conversamos. Mcu pai não falou por muitos minutos... Nós três continuamos a comer em silêncio. Sentamo-nos e permanecemos em silêncio por alguns minutos... Caimos novamente em silêncio... Ficamos em silêncio novamente...

6 ISHIGURO, op.cit., p. 434-35.

7 Ibid., p.435, 439, 440, 441, 442. 
Além dessa impossibilidade de comunicação, o pai reitera algumas vezes seu inconformismo por ter "perdido" o filho e sugere que ele, o filho, $\dot{e}$ responsável pela morte da mãe. Paralelo à revolta, o desejo paterno de ter novamente os fillhos a sua volta - a permanência do filho em sua casa e o retorno de Kikuko, que está cursando seu último ano na Universidade em Osaka encontra expressão mais contundente na narrativa através da metáfora mais representativa do texto em relação à situação familiar: as canhoneiras mal coladas.

Um pouco antes do jantar, ao levar o filho para ver novamente a casa, o velho pai tenta explicar que scu passatempo predileto no momento é montar navios de guerra de plástico, já que agora dispõe de mais tempo para si. Entre os muitos quartos vazios da casa, sobre uma mesa envolta pela penumbra, pai e filho observam o navio de guerra de plástico cinza. Ao observá-lo, o pai afirma: "Estas pequenas canhoneiras aqui deveriam ser mais bem coladas, não acha?" Ao que o filho responde: "Talvez. Acho que está bem." $\mathrm{A}$ idéia de que as canhoneiras devam estar bem coladas exprime de forma metafórica o que muitas vezes de forma aberta ou velada o pai já afirmara: que os filhos devem ficar permanentemente ligados aos pais, à família e ao pais.

É durante essa mesma excursão pela casa que o problema existencial do pai revela-se paradoxalmente muito semelhante ao do filho. $O$ primeiro menciona que a casa está muito grande agora que está só, que ele se encontra rodeado de quartos vazios. O lilho, por sua vez, ao ser questionado por Kikuko sobre a namorada americana Vicki, responde: “Acabou tudo. Não há muita coisa para mim agora na Califórnia." Ao mostrar a semelhança entre a situação existencial do fillho e do pai, e a insegurança de Kikuko que, apesar de gostar do namorado, não se sente pronta para abandonar os amigos e passar todo seu tempo ao lado dele, Ishiguro parece estar mostrando ao leitor que não importa sua origem, não importam seus valores, nāo importam as decisōes existenciais, atualmente, os membros da nova geração também têm que enfrentar a ambivalência, a dissolução e o caos existencial. Essa situação é semellante à da velha geração que vê, na dissolução da sociedade e dos costumes, a destruição do próprio ser.

$O$ texto, antes de iniciar sua narrativa ficcional propriamente dita, introduz uma descrição dos efeitos "quase sempre" ${ }^{10}$ mortais do peixe fugu.

$9 \quad$ Ibid., p.437.

10 lbid., p.434. 
Fugu é um peixe encontrado nas águas japonesas do Pacífico. Esse peixe tem um significado especial para mim por ter causado a morte de minha mãe. $O$ veneno é armazenado nas glândulas sexuais do peixe, dentro de duas frágeis bolsas. Ao prepará-lo, essas bolsas devem ser removidas com cuidado, pois qualquer descuido fará com que o veneno penetre nas veias. Lamentavelmente, não se pode saber se essa operação foi bem sucedida. Só teremos a prova, afinal das contas, ao comer.

$O$ envenenamento por fugu é terrivelmente doloroso e quase sempre fatal. Se o peixe for ingerido ao jantar, a vitima é geralmente tomada pela dor durante o sono. Ela se contorce em agonia por algumas horas e amanhece morta. ${ }^{11}$

Um tanto peculiar esse início, mas aos poucos o leitor perceberá o valor da informação. De uma descrição que parece nada ter a ver com prosa ficcional somos levados a estabelecer o primeiro vínculo entre o tex to e o subtexto. Há referência explícita na citação acima e no terceiro parágrafo da mesma página que a mãe do narrador, de livre e espontânea vontade, ao contrário de seu hábito de não comer fugu, aceita o peixe of crecido por uma amiga e morre em conseqüência de envenenamento. A lembrança da mãe é evocada na narrativa principalmente através de duas imagens: a imagem da velha ao lado do poçouma imagem que já assombrava o local quando Kikuko e seu irmão eram pequenos - e a imagem da mãe envelhecida, perpetuada na foto que se esconde na escuridão da sala quando a familia se reúne para jantar. A semelhança entre a descrição da foto e a imagem da velha ao lado do poço, além da mágoa várias vezes externalizada pelo pai de que a mãe teria cometido suicídio por desgosto de ter sido abandonada pelo fillho, envolve a lembrança da mảe com uma névoa lúgubre e funesta.

$\mathrm{Na}$ opiniāo de Kikuko, a mãe tinha consciência de ter dado mais atenção à criação da filha que, segundo a mãe, diz Kikuko com um sorriso malicioso, fizera com que a filha se tornasse muito melhor do que o irmão. Vemos através do texto, no entanto, que Kikuko desenvolveu um comportamento duplo - de um lado é a filha "bem comportada" na presença dos pais, de outro, é uma cópia do seu irmão, com sonhos de independência e aventura. Não há indicios no texto de que o pai percebe a duplicidade do comportamento da filha, não há indicios tampouco que a mãe percebera que Kikuko era realmente uma jovem com caracteristicas de personalidade anacardium orientalis, ou seja, dissimuladora -irônico resultado da atenção especial que tinha sido dedicada à fillha.

11 ISHIGURO, op.cit. 
Não é surpreendente portanto, considerando que a imagem da velha do poço e a imagem da mãe são exploradas pelo narrador como incrivelmente semelhantes, que os locais onde as duas "permanecem" são os espaços ficcionais mais simbólicos do texto: o poço e a sala de jantar.

No inicio do conto, quando Kikuko entra em casa e confronta-se com seu querido irmão, ela só se sente bem ao afastá-lo da casa e levá-lo ao poço, local das brincadeiras infantis de ambos. Ao assim fazer, Kikuko sente-se liberta do comportamento que é "forçada" a ter na presença do pai. Ela pode fumar livre e dramaticamente, falar de sua vida em Osaka, de seus sonhos e preocupações - atitudes e assuntos que não toma ou não aborda na frente do pai.

Minha irmã relaxou a olhos vistos assim que ele [o pai] deixou a sala. Em poucos minutos, estava tagarelando livremente sobre seus amigos em Osaka e as aulas na universidade. Então, repentinamente, ela decidiu que deveríamos andar pelo jardim e apressou-se em direção à varanda. caminhamos para o jardim. A luz do dia havia quase desaparecido.

"Estou morrendo de vontade de fumar desde que cheguei", ela disse, acendendo um cigarro.

"Então por que você não fumou?"

Ela gesticulou furtivamente em direção à casa, então sorriu maliciosamente.

"Entendi", eu disse. ${ }^{12}$

Quando o narrador chegara na casa de seu pai e avistara o poço da sala de estar, este já estava envolto pela penumbra. Gradativamente a penumbra cede lugar à escuridão. Ao voltarem para casa, a sala de jantar está também mal iluminada. A penumbra impera no espaço onde os personagens sentam-se - no chão, ao redor da mesa, para saborear o ensopado de peixe preparado pelo pai. Além desse espaço restrito, impera a escuridão. A fumaça que sai da sopeira sobe de forma encaracolada até a fraca lâmpada que ilumina a mesa, estabelecendo assim um outro vínculo do tex to com o subtexto, ou seja, da descrição do envenenamento por fugu, que leva a vítima a contorcer-se de dor durante toda uma noite, se ingerido no jantar, e a morrer na madrugada. ${ }^{13} \mathrm{O}$ fato do envenenamento por fugu ser quase sempre fatal, possibilita ao narrador apresentar sua narrativa em $1^{\text {a }}$ pessoa. Não devemos nos adiantar, no entanto, e

13 Ver citação na p.145 deste trabalho. 
concluir que o velho pai realmente deseja a morte de seus filhos e a sua própria morte. Há muitos indícios no tex to de que esse é realmente o desejo do pai; há concomitantemente, no entanto, evidências, em número menor, de que o desejo do pai é realmente ter os filhos novamente ao seu redor e apenas isso.

Resumindo, entre as evidências que levam o leitor a concluir que o pai realmente estava preparando ensopado de fugu envenenado para si e para os filhos, temos:

1. antes do jantar: a preocupação do narrador em iniciar seu texto descrevendo os efeitos quase sempre fatais da ingestão de fugu envenenado; ${ }^{14}$ a constante preocupação do pai através do texto com a fome do filho parece revelar um desejo de que o filho tenha realmente se alimentado mal no avião, que esteja faminto e não seja capaz de rejeitar o jantar ou comer pouco; a referència à morte da mãe por envenenamento por fugu, o que faria com que o pai, em respeito à sua memória, forçasse o mesmo destino sobre toda a familia a semelhança de Watanabe; ${ }^{15}$ o pai considera a atitude de seu amigo Watanabe - que matou toda a família e se suicidou depois da falência da firma - uma atitude de um homem de princípios e honra, enfim um homem para ser imitado; ${ }^{16}$ a preocupação constante do pai em querer saber se o filho está de volta para fïcar ou não - o próprio pai chega à conclusão de que o fillho se arrependeria se ficasse; ${ }^{17}$ o pai deixa claro que não quer que ninguém o ajude na preparação do jantar, ele só solicita a ajuda de Kikuko com alguns legumes quando o ensopado já está quase pronto; ${ }^{18}$ a revolta que o pai expressa constantemente contra a atitude do fillho de ter abandonado o Japão; a penumbra e a cscuridão envolvem o espaço ocupado pelos personagens desde o início da narrativa; a afirmação do pai, ao falar que gostaria de ter pertencido a força aćrea durante a guerra mundial, porque pilotando-se um avião haveria sempre a possibilidade de uma "última cartada" ao ser atingido; ${ }^{19}$ a impossibilidade de superar o rancor e estabelecer um diálogo aberto com os fillhos durante toda a narrativa;

2. durante o jantar: a sugestão simbólica da penumbra que envolve a mesa e da escuridão que envolve a sala; ${ }^{20}$ a sugestão simbólica do encaracolar-se da fumaça em direção a fraca lâmpada sobre a mesa estabelecendo um paralelo entre o movimento da mesma e o contorcer-se da vítima por envenenamento por

ISHIGURO, op. cit., p.436.

lbid.

lbid., p.435, 438, 441 .

Ibid., p.439,442.

lbid., p.437, 438.

lid., p.438.

lbid., p.439. 
fugu; ${ }^{21}$ a resposta reticente do pai ao ser questionado pelo filho sobre qual era o peixe com cheiro tão delicioso, o pai responde: "Apenas peixe"; ${ }^{22}$ o furor do pai quando o filho não reconhece a própria mãe ao perguntar quem é a mulher na foto da parede da sala; ${ }^{23}$ a insistência do pai para que seus fillhos se sirvam em abundância; ${ }^{24}$

3. depois do jantar: ao passarem para outra sala para aguardar o chá que está sendo preparado por Kikuko, o poço não pode mais ser visto, pois a escuridão do lado de fora é total; ${ }^{25}$ pela primeira vez, ao terem comido todo o ensopado, o pai parece relaxado - estica os braços e respira com satisfação; ${ }^{26}$ a afirmação feita pelo pai, que pode ser tomada ironicamente, de que sem dúvida o filho voltará para a América - como que para justilicar sua ação de servir peixe envenenado; ${ }^{27}$ o silêncio que impera no final do texto. ${ }^{28}$

Entre as poucas evidèncias que levam o leitor a considerar que o pai não cometeria um ato insano como matar seus dois filhos e se suicidar, temos: a existência do narrador, que pode, no entanto, ser interpretada como sendo um dos sobreviventes do envenenamento "quase sempre fatal" por fugu; a tentativa do pai de justificar a atitude do filho, dizendo que este tinha sido levado por más influências; ${ }^{29}$ por um momento durante o conto o pai sorri de modo estranho, "quase gentil"; $;$ a culpa de ter sido um pai ausente e o implícito desejo de remediar a atitude do passado; ${ }^{31}$ ao ser questionado pelo fillo sobre sua opinião em relação a atitude de Watanabe, ao matar a familia e se matar, o pai responde que não concorda com a atitude de Watanabe, pois existem outras coisas além do trabalho; ${ }^{32}$ o pai diz ao filho, após o jantar, que se ele quiser ficar em sua casa, "seria muito bem-vindo. Isto é se ... [ele] não se importar em morar com um velho"; 33 a esperança que o velho parece ter que Kikuko, após terminar os estudos dentro de um ano, volte para casa. "Talvez ela queira voltar para casa

lbid., p.441.

lbid., p.440.

lbid., p.440, 44l.

lbid., p.442.

Ibid., p.441.

Ibid., p.442.

lbid.

lbid., p.435.

Ibid., p.439.

Ibid.

Ibid., p.441.

Ibid., p.442. 
então. Ela é uma boa menina"; ${ }^{34}$ a última afirmação do pai no conto é positiva: "As coisas vão melhorar então." 35

Considerando-se essas evidências, a narrativa de Ishiguro mostra-se muito renitente e fechada à revelação do mistério da diegese e do seu próprio mistério. O que pode parecer, no entanto, uma dificuldade a ser transposta, acaba por se transformar em um texto encantador e em uma busca incessante. Uma Pálida Visão dos Montes e Um Artista do Mundo Flutuante lançam o mesmo desafio ao leitor.

\section{RESUMO}

Este trabalho sobre o conto "Jantar em Familia" de Kazuo Ishiguro tenta mostrar o diálogo existente entre texto e subtexto e a impossibilidade de se chegar a qualquer resposta conclusiva em relação ao grande questionamento suscitado pelo subtexto. São inúmeras as evidências no texto para uma reposta afirmativa, são menos numerosas mas não menos importantes as evidências para uma resposta negativa. Resta ao leitor satisfazer-se com a impossibilidade de encontrar uma resposta definitiva.

Palavras-chave: crítica literária, Literatura Inglesa, conto.

\section{ABSTRACT}

This paper on "Family Supper," by Kazuo Ishiguro, tries to demonstrate the dialogue between the text and the subtext and the impossibility to find any definite answer to the question raised by the subtext. There are many evidences in the text to formulate a positive answer; there are also, however, several evidences for a negative answer. It remains impossible, however, for the reader to find a conclusive answer.

34 ISHIGURO, op.cit.

35 lbid. 


\section{REFERÊNCIAS BIBLIOGRÁFICAS}

ISHIGURO, K. A Pale View of Hills. New York : Vintage Books, 1982. . An Artist of the Floating World. New York : Vintage Books, 1986. . Remains of the Day. New York: Vintage Books, 1988.

. "Family Supper". In: BRADBURY, M. ed. The Penguin Book of Modern British Short Stories. England : Penguin Books, p. 434-442. Tradução de Brunilda Tempel Reichmann. 